\title{
A NEW TECHNIQUE FOR SAFE AND NERVE PRESERVING TOTAL MESORECTAL EXCISION
}

\author{
Kiril G. Kirov, \\ Research Institute, \\ Medical University - Pleven, \\ Bulgaria
}

\begin{abstract}
Summary
Our purpose was to present a technique of pneumodissection applied with total mesorectal excision that ensured effective pelvic nerve preservation. Its detailed description emphasized the role of the proper definition of optimal dissection plane around the rectal cancer, the so-called 'holy plane' for total mesorectal excision. The study covered 28 rectal cancer patients at a mean age of $58 \pm 7.6$ years (range 53 to 69 years). Rectal cancers were of TNM stages I-III and differentiation grades of G1-G3. Total mesorectal excision with pneumodissection between 2011 and 2016 was performed. Inflation of the pararectal space with $\mathrm{CO}_{2}$ improved visualization of the operative field between visceral and parietal fascia thus preserving plexus (pl.) vesicalis, pl. deferentialis, pl. prostaticus and pl. cavernosus penis. A fast and clean mesorectum mobilization was made without any damage to the visceral fascia, and total mesorectal excision was performed in the embryonal plane. Pl. hypogastricus superior in the region of the aortic bifurcation nervi (nn.) hypogastrici dextri et sinistri laterally to the rectum and pl. hypogastricus inferior were preserved, too. Encouraging postoperative results included pelvic nerve preservation and absence of complications. A broader application of the safe method of pneumodissection in open and laparoscopic rectal cancer surgery should be recommended.
\end{abstract}

Keywords: rectal cancer, total mesorectal excision, pneumodissection, pelvic nerve preservation

\section{Introduction}

According to R. Heald (1998) [1], a surgical plane is a potential space between contiguous organs which can be reproducibly created by dissection. A clue to the existence of the plane is provided by a glimpse, through the window of its peritoneal covering, of mobility between a visceral structure (e.g. the mesorectum) and the somatic structures, which surround it.

Surgeons should follow the 'holy plane' described by Heald between the perirectal fascia and the pelvic fascia in order to totally excise the mesorectum, and to preserve the autonomic pelvic nerves comprising the superior hypogastric plexus (pl.), the right and left hypogastric nerves as well as the right and left inferior hypogastric pls. [2]. A rectal surgeon should attempt to define an optimal dissection plane around the rectal cancer which must clear all forms of extension and 
circumscribe predictably uninvolved tissues [1]. An optimal total mesorectal excision for rectal cancer can be done by dissection in front of Denonvillier's fascia [3].

Anatomic observations of the 'holy plane' for total mesorectal excision demonstrate that rectovesical septum is formed by the ventral part of the fascia propria and Denonvillier's fascia without any blood vessels and nerves [4]. The lateral rectal space is between the lateral part of the fascia propria and the parietal fascia and is traversed (crossed) by pelvic nerve pl. and lateral ligament of the rectum

Histological examination of the perirectal fascia and the pelvic autonomic nerves in human adult cadaveric specimens indicates that the mid- and lower rectum is surrounded by a multilayered perirectal fascia, of which the mesorectal and parietal fasciae border the 'holy plane [5]. There is no extra permanent fascia forming a potential surgical plane. Nerves run laterally to the mesorectal fascia.

The purpose of this communication is to describe a new technique for uneventful total mesorectal excision enabling effective pelvic nerve preservation. It deals with the method of pneumodissection in open rectal cancer surgery.

\section{Materials and Methods}

During the period between January 1 $1^{\text {st }}, 2011$ and December $31^{\text {st }}$, 2016, a total of 28 rectal cancer patients at a mean age of $58 \pm 7.6$ years (range 53 to 69 years) underwent total mesorectal excision with application of the method of pneumodissection, as described above in Marko Markov Specialized Hospital for Oncologic Diseases of Varna, Bulgaria. Main demographic patients' characteristics are shown on Table 1.

Table 1. Demographic patient's characteristics

\begin{tabular}{lllll}
\hline \multirow{2}{*}{ Parameters } & males & \multicolumn{2}{c}{ females } \\
\cline { 2 - 5 } & $\mathrm{n}$ & $\%$ & $\mathrm{n}$ & $\%$ \\
\hline gender & 16 & 57.14 & 12 & 42.86 \\
\hline mean age (years) & $57 \pm 6.1$ & & $59 \pm 8.2$ & \\
\hline age range (years) & $54-63$ & \multicolumn{2}{c}{$53-69$} & \\
\hline
\end{tabular}

TNM stage, differentiation grade and ASA grade of rectal cancer are listed on Table 2.
Table 2. Rectal cancer characteristics

\begin{tabular}{lll}
\hline Rectal cancer parameters & $\mathrm{n}$ & $\%$ \\
\hline TNM stage & & \\
\hline I & 9 & 32.14 \\
\hline II & 12 & 42.86 \\
\hline III & 7 & 25.00 \\
\hline Differentiation grade & & \\
\hline G1 & 5 & 17.86 \\
\hline G2 & 20 & 71.43 \\
\hline G3 & 3 & 10.71 \\
\hline ASA grade & & \\
\hline I & 6 & 21.43 \\
\hline II & 18 & 64.29 \\
\hline III & 4 & 14.2 \\
\hline
\end{tabular}

\section{Technique description}

Both the rectum and mesorectum are of the same embryonic origin and are considered as a lymphovascular entity [6]. Bearing in mind these embryonic peculiarities and the relationships between fasciae and spaces around sigmoid colon and rectum, it has been established that the existing surgical structures could be easily defined and differentiated by means of the pneumodissection method $[7,8]$.

The peritoneum is punctured with Veress needle or another longer needle. The peritoneum is punctured in the most distal region of sigmoid colon in close proximity of its transition into the rectum.

The needle should glide in from of the aortic bifurcation in the area of the promontorium (Figure 1) remaining between the prerenal fascia and visceral fasciae of the rectum and sigmoid colon.

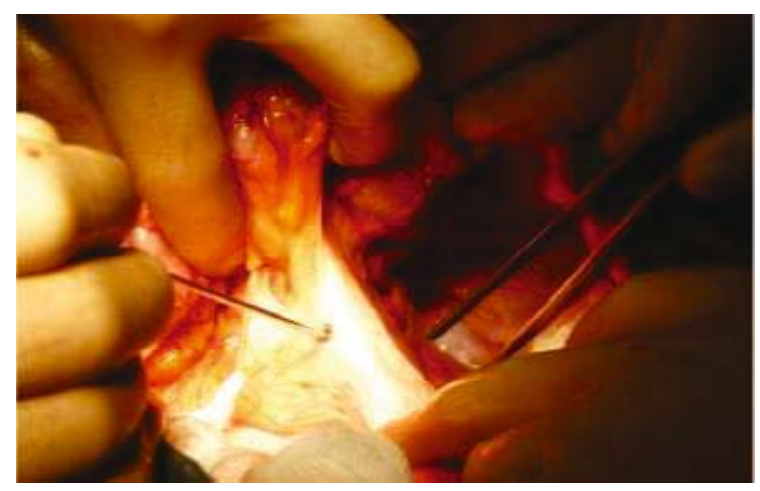

Figure 1. Initial puncture point 
The needle is connected with a $\mathrm{CO}_{2}$ insufflator and pararectal space is inflated with a moderate amount of the gas (Figure 2).

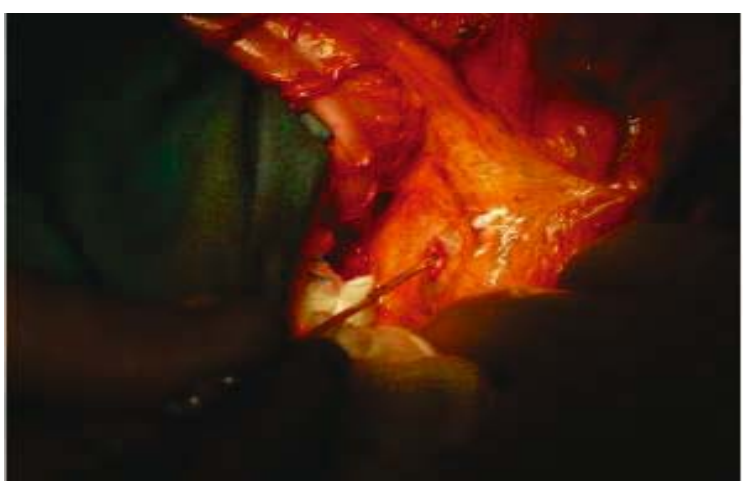

Figure 2. Beginning of $\mathrm{CO} 2$ insufflation

The gas mobilizes the mesocolon located above the prerenal fascia that covers the vascular structures, autonomic nerves, i.e. pl. aorticus abdominalis, the gonadal vessels and the ureter. They are visualized extraordinarily well during the subsequent cutting of the peritoneum that facilitates their preservation. The gas pushes caudally in the loose connective tissue between the parietal and visceral sheets, mobilizes them and enlarges the retrorectal space, thus entering the 'holy plane'. The visceral and parietal fasciae are divided by the air as the nerves remain like small bridges. This enables the preservation of the hypogastric nerves following the interruption of the nerves entering the rectal wall (Figure 3).

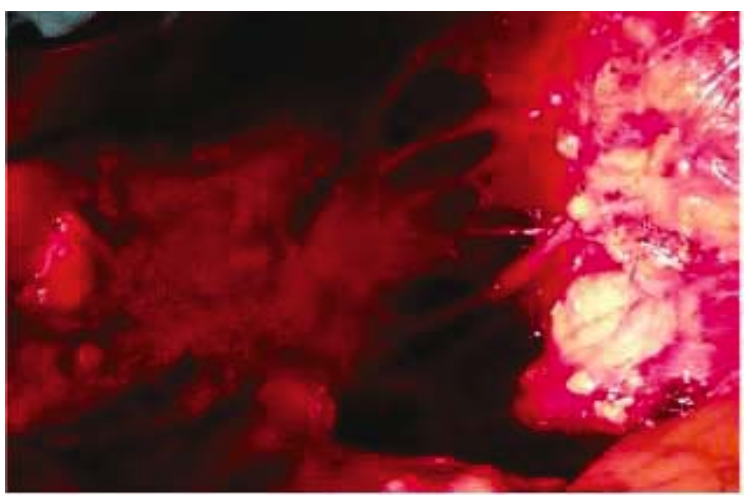

Figure 3. Inflated retrorectal space

After inflation, the needle is placed into the rectovesical or rectouterine fold, respectively, between Denonvilliers' fascia and the mesorectal visceral sheet. A definite gas volume is insufflated there. $P l$. vesicalis, pl. deferentialis, pl. prostaticus and pl. cavernosus penis remain in front of Denonvilliers' fascia and are preserved.
This allows for fast and clean mesorectum mobilization without any damage to the visceral fascia, i.e. the performance of total mesorectal excision on an embryonic plane. The structures covered by the urogenital fascia such as pl. hypogastricus superior in the region of the aortic bifurcation; nn. hypogastrici dextri et sinistri laterally to the rectum and pl. hypogastricus inferior are also preserved (Figure 4).

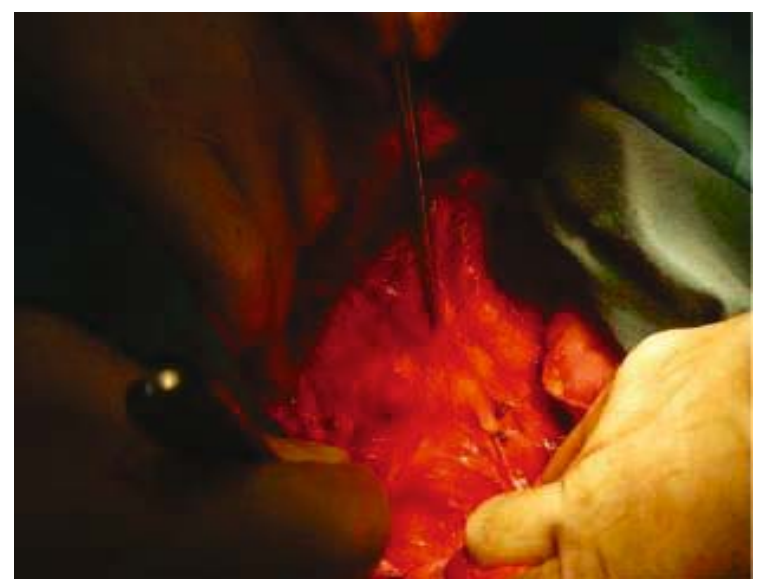

Figure 4. Upper hypogastric plexus and hypogastric nerves

The peritoneum is dissected. Afterinterruption of the connective tissue ligament between the rectal and parietal fasciae in the region of sacral crest by using scissors or ultrasonic scalpel, penetration is achieved between the parietal and visceral sheets in the small pelvis. Sometimes the inflated air mobilizes the hypogastric nerves from the visceral and parietal fasciae resulting in an interesting phenomenon of 'nerves in the air' (Figure 5).

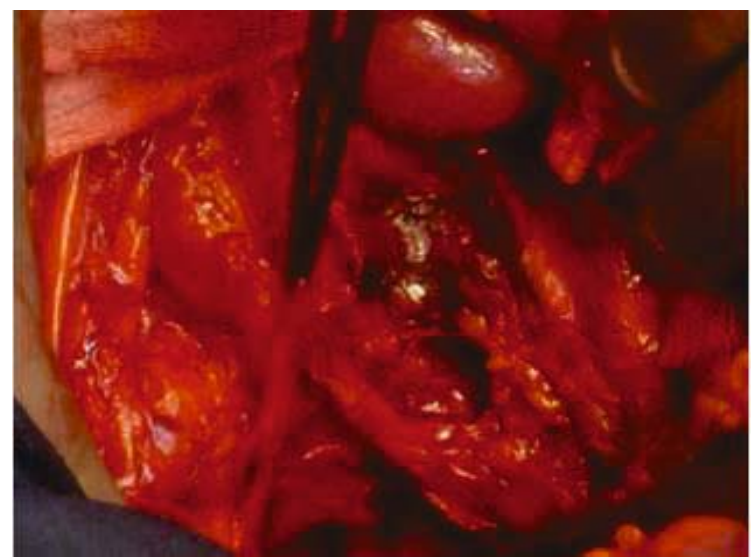

Figure 5. 'Being of nerves in the air'phenomenon

The plane created by insufflating gas into the retrorectal space resulting from 
pneumodissection is easy to follow through cutting the single small bridges along the hypogastric nerves towards the rectum. The lateral ligaments should be interrupted as close as possible to the rectal fascia if the fascia is not involved in the tumour process in order to preserve the distal part of $\mathrm{pl}$. hypogastricus inferior and its branches to the genital system. The air does not mobilize both fasciae when the neoplasm sprouts outside the visceral fascia. This indicates the enlargement of the circumferential resection line and transition to a presacral plane of posterior mobilization. It is noteworthy that the dissection plane is lost, autonomic nerve structures are damaged and vessels of venous sacral pl. are injuried. With tumours fixed on the anterior wall, the surgeon passes to the extramesorectal plane and 'en bloc' resection with Denonvillier's fascia should be performed. During the complete rectum mobilization in the retrorectal and prerectal spaces outside the rectal fascia following the dissection of the lateral ligaments and the rectosacral fascia, a united perirectal space is formed located around the entire circumferentia of the rectal fascia. A properly mobilized mesorectum looks like a bilobar lipoma because of its central pulling by the anococcygeal ligament. Both lobes reflect the pair of fossae formed by the levator muscles. This manner of pneumodissection enables a fast and clean mobilization of abdominal and small pelvic tissues and structures in conformity with 'holy plane' identified by means of this method.

\section{Results}

Some essential surgical parameters of the patients having undergone open or laparoscopic proctectomy with pneumodissection were compared on Table 3.

Table 3. Surgical parameters after open and laparoscopic proctectomy with pneumodissection

\begin{tabular}{lllll}
\hline Parameters & \multicolumn{2}{l}{ open surgery $(\mathrm{n}=16)$} & \multicolumn{2}{l}{ laparoscopic surgery $(\mathrm{n}=12)$} \\
\hline operative time (min.) & $105.1 \pm 13.5$ & $90-132$ & $211.2 \pm 27.3$ & $175-260$ \\
\hline intraoperative blood loss $(\mathrm{mL})$ & $278.7 \pm 60.7$ & $170-593$ & $173.1 \pm 32.4$ & $115-220$ \\
\hline drainages (mL) & $321.6 \pm 106.4$ & $185-614$ & $181.6 \pm 44.5$ & $140-230$ \\
\hline flatus (day) & $3.0 \pm 0.8$ & $2-4$ & $2.4 \pm 1.1$ & $1-3$ \\
\hline begin of feeding (day) & $3.2 \pm 0.8$ & $2-5$ & $2.6 \pm 1.4$ & $1-4$ \\
\hline postoperative hospital stay (days) & $7.0 \pm 2.9$ & $5-13$ & $6.3 \pm 1.9$ & $4-8$ \\
\hline postoperative moving (day) & $2.0 \pm 0.7$ & $2-4$ & $1.4 \pm 0.8$ & $1-2$ \\
\hline removed lymph nodes (n) & $11.7 \pm 3.8$ & $7-15$ & $12.4 \pm 3.0$ & $7-15$ \\
\hline
\end{tabular}

Laparoscopic interventions by means of pneumodissection proved to surpass open surgery in terms of smaller intraoperative blood loss and drainage amounts, earlier flatus, feeding and postoperative moving as well as shorter postoperative hospital stay.

\section{Discussion}

Rectal cancer surgery history of more than a hundred years outlines the role of abdominoperineal resection, Hartmann's procedure, anterior rectal resection, total mesorectal excision, transanal total mesorectal excision and laparoscopic surgery as gold standard treatments for further improvement of both oncological outcomes and patients' quality of life [9]. Here belong several minimally invasive technique approaches such as transanal endoscopic microsurgery, transanal minimally invasive surgery, and natural orifices transluminal endoscopic surgery [10]. The first transanal total mesorectal excision was successfully performed in a 76-year-old female patient with a T2N2 rectal cancer given preoperative chemoradiation [11]. A detailed stepwise description of a technique of a bottom-up approach to the mesorectal plane for complete mesorectal excision ensuring the optimal outcomes of oncologic treatment was reported [12].

There is an on-going debate about the use of laparoscopic proctectomy for rectal cancer. Several randomized trials have shown that shortterm outcomes and perioperative morbidity and mortality of laparoscopic proctectomy in the management of rectal cancer are equivalent to open surgery [13]. Preservation of Denonvilliers' fascia during laparoscopic resection for mid-low 
rectal cancer effectively protects male urinary and sexual functions [14]. In a multicenter, balanced, ACOSOG Z6051 randomized trial, laparoscopic resection of stage II or III rectal cancer failed to meet the criterion for noninferiority for pathologic outcomes to open resection as determined by gross pathologic and histologic evaluation of the resected proctectomy specimen [15]. The efficacy, morbidity and functional outcome of laparoscopic proctectomy are to be compared with transanal endoscopic proctectomy for low-lying rectal cancer in a multicenter randomized controlled trial [16].

Laparoscopic transanal total mesorectal excision was carried out in 102 patients using pneumodissection of retroperitoneal structures to facilitate laparoscopic rectal resection [17]. The mean operative time was $185.0 \pm 87.5 \mathrm{~min}$. (range, $60-480 \mathrm{~min}$.), and there was no conversion to open surgery. Postoperative morbidity rate was $33.3 \%$, and mortality rate at 30 days was $1.96 \%$ (two lethal cases).

Our own results are encouraging. Herewith we confirm that the method of pneumodissection ensures a very good visibility of the operative field and considerably facilitates the surgical intervention in rectal cancer patients. In our contingent, there were neither early nor late postoperative complications. This technique warrants effective pelvic nerve preservation during abdominal surgery. Our initial experience with laparoscopic proctectomy demonstrates similar results $[7,8]$.

\section{Conclusions}

Based on our experience and literature data available, we could recommend a broader application of the safe method of pneumodissection in open and laparoscopic rectal cancer surgery.

\section{Acknowledgements}

This is an original study that has not been supported by any means.

\section{Disclosure of interest}

The authors report no conflicts of interest.

\section{References}

1. Heald RJ. The 'Holy Plane'of rectal surgery. J R Soc Med. 1988;81(9):503-8.

2. Faucheron JL. Pelvic anatomy for colorectal surgeons. Acta Chir Belg. 2005;105(5):471-4.

3. Heald RJ, Moran BJ, Brown G, Daniels IR. Optimal total mesorectal excision for rectal cancer is by dissection in front of Denonvilliers fascia. Br J Surg. 2004;91(1):121-3.

4. Wang SD, Deng XF, Han H, Chang JC, Cao $\mathrm{XD}$, Zhang M. [Anatomical observation of the 'holy plane' for total mesorectal excision]. Zhonghua Wei Chang Wai Ke Za Zhi. 2011;14(1):44-7. Chinese.

5. Kraima AC, West NP, Treanor DR, Magee DR, Bleys RLAW, Rutten HJT, et al. Understanding the surgical pitfalls in total mesorectal excision: Investigating the histology of the perirectal fascia and the pelvic autonomic nerves. Eur J Surg Oncol. 2015;41(12):1621-9.

6. Heald RJ. A new approach to rectal cancer. Br J Hosp Med. 1979;22(3):277-81.

7. Kirov KG, Kobakov GL, Bogdanov BG. [Application of the method of pneumodissection in conventional and laparoscopic rectal operations]. Onkologiya. 2015;43(3):30-5. Bulgarian.

8. Kirov KG. [Optimization of the results from conventional and laparoscopic colorectal resections] [dissertation]. Sofia: Specialized Hospital of Oncology of Sofia; 2015. Bulgarian.

9. Lirici MM, Hüscher CG. Techniques and technology evolution of rectal cancer surgery: a history of more than a hundred years. Minim Invasive Ther Allied Technol. 2016;25(5):226-33.

10. Trépanier JS, Fernandez-Hevia M, Lacy AM. Transanal total mesorectal excision: surgical technique description and outcomes. Minim Invasive Ther Allied Technol. 2016;25(5):234-40.

11. Sylla P, Rattner DW, Delgado S, Lacy AM. NOTES transanal rectal cancer resection using transanal endoscopic microsurgery and laparoscopic assistance. Surg Endosc. 2010;24(5):1205-10.

12. Knol J, Chadi SA. Transanal total mesorectal excision: technical aspects of approaching the mesorectal plane from below. Minim Invasive Ther Allied Technol. 2016;25(5):257-70.

13. Atallah C, Efron JE. Laparoscopy for rectal cancer. Clin Colon Rectal Surg. 2017;30(2):10411.

14. Wei HB, Fang JF, Zheng ZH, Wei B, Huang $\mathrm{JL}$, Chen TF, et al. Effect of preservation of Denonvillier's fascia during laparoscopic resection for mid-low rectal cancer on protection of male urinary and sexual functions. Medicine (Baltimore). 2016;95(24):e3925. 
15. Fleshman J, Branda M, Sargent DJ, Boller AM, George V, Abbas M, et al. Effect of laparoscopicassisted resection vs open resection of stage II or III rectal cancer on pathologic outcomes: The ACOSOG Z6051 randomized clinical trial. JAMA. 2015;314(13):1346-55.

16. Lelong B, de Chaisemartin C, Meillat H, Cournier $\mathrm{S}$, Boher JM, Genre D, et al. A randomized controlled trial to evaluate the efficacy, morbidity and functional outcome of endoscopic transanal proctectomy versus laparoscopic proctectomy for low-lying rectal cancer (ETAP-GRECCAR 11 TRIAL): rationale and design. BMC Cancer. 2017;17(1):253.

17. Hüscher CGS, Lirici MM. Transanal total mesorectal excision: pneumodissection of retroperitoneal structures eases laparoscopic rectal resection. Dis Colon Rectum. 2017;60(10):110912. 